\title{
DESENVOLVIMENTO E COMPOSIÇÃO CORPORAL DE ALEVINOS DE JUNDIÁ (Rhamdia quelen) ALIMENTADOS COM DIETAS CONTENDO DIFERENTES FONTES DE LIPÍDIOS
}

\author{
DEVELOPMENT AND BODY COMPOSITION OF SOUTH AMERICAN CATFISH \\ (Rhamdia quelen) FINGERLINGS FED WITH DIFFERENTS LIPID DIETARY SOURCES
}

\author{
José Fernando Bibiano Melo ${ }^{1}$ João Radünz Neto ${ }^{2}$ José Henrique Souza da Silva $^{3}$ \\ Carlos Guilherme Trombetta ${ }^{1}$
}

\begin{abstract}
RESUMO
Foram testadas três fontes de lipídios em rações experimentais para juvenis de jundiá Rhamdia quelen com a inclusão de $5 \%$ na dieta de óleo de canola (T1), óleo de fígado de bacalhau (T2) ou banha suína (T3), usando o delineamento inteiramente casualizado com três tratamentos e três repetições. $O$ desempenho e o rendimento de carcaça não foram afetados pelas fontes de lipídios testadas, porém estas influenciaram na maior deposição de proteína na carcaça dos peixes do tratamento T1 e de gordura na carcaça no tratamento T3.
\end{abstract}

Palavras-chave: ganho de peso, gordura dietária, jundiá, Rhamdia.

\section{SUMMARY}

Three sources of lipids, canola oil (T1), cod liver oil (T2), and swine fat (T3), were tested in experimental rations for juveniles of jundia (Rhamdia quelen), representing 5\% of their diet. A completely randomized design with three treatments (T) and three repetitions was used. The performance and the carcass yield were not affected by the three lipids. The lipids sources influenced the protein (high value on T1) and fat (high value on T3) deposition in the carcass.

Key words: weight gain; diet lipids; jundiá, Rhamdia.

\section{INTRODUÇÃO}

A utilização de fontes lipídicas em dietas para peixes tem proporcionado melhores resultados no desenvolvimento, sobrevivência e deposição de nutrientes. Os lipídios são considerados fontes importantes de energia metabólica, sendo compostos mais energéticos que as proteínas e os carboidratos (FARKAS et al., 1977). Também desempenham importantes funções em processos fisiológicos, mantendo a permeabilidade e flexibilidade das membranas celulares (CHO et al., 1985; STICKNEY \& HARDY, 1989). Além disso, são considerados importantes fontes de ácidos graxos essenciais (AGE), exercendo influência sobre a presença destes no corpo dos peixes, quando presentes na ração (GATLIN \& STICKNEY, 1982). Determinados ácidos graxos não podem ser sintetizados pelos peixes quando não forem encontradas na dieta as substâncias precursoras (NICOLAIDES \& WOODALL, 1962). Vários estudos comprovaram que os lipídios são fontes indispensáveis ao bom desempenho das larvas e alevinos de peixes, variando, porém, sua concentração em função de fatores como espécie, tipo de ambiente (água doce ou salgada), temperatura do meio onde vivem e, provavelmente, estádio de desenvolvimento do peixe (larva-adulto) (LÉGER, 1980). Com relação às fontes de lipídios utilizadas na alimentação de peixes, a proporção de AGE é variável. As quantidades dos ácidos graxos, requeridos por algumas espécies já estudadas, segundo o NRC (1993), variam em função das fontes utilizadas. São encontrados no óleo de fígado

\footnotetext{
${ }^{1}$ Zootecnistas, Alunos do Curso de Pós-graduação em Zootecnia, Universidade Federal de Santa Maria.(UFSM).

2 Engenheiro Agrônomo, Professor Adjunto, Doutor, Departamento de Zootecnia (DZ), Centro de Ciências Rurais, (UFSM), Santa Maria, RS, 97105-900. Bolsista CNPq. E-mail: radunz@ ccr.ufsm.br

${ }^{3}$ Engenheiro Agrônomo, Professor Adjunto, PhD, DZ-UFSM.
} 
de peixe $27 \%$ de $\mathrm{AG}(\mathrm{n}-3)$ e $3 \%$ de (n-6); na banha suína $1 \%$ de (n-3) e 10,2\% de (n-6); e no óleo de canola $12 \%$ de AG (n-3) e 20,2\% de (n-6). Assim, o presente trabalho teve como objetivo verificar o efeito de três fontes de lipídios no desenvolvimento e composição corporal de alevinos de jundiá Rhamdia quelen.

\section{MATERIAL E MÉTODOS}

O experimento foi realizado no setor de Piscicultura do Departamento de Zootecnia da Universidade Federal de Santa Maria, num período de 26 dias. Foram testados três tratamentos, usandose rações granuladas preparadas à base de fígado bovino (66\% de proteína bruta) e levedura de álcool (40\% de proteína bruta), incluindo-se $5 \%$ de óleo de canola (T1), óleo de fígado de bacalhau (T2) ou banha suína (T3) (Tabela 1). As rações foram preparadas no próprio setor, onde as matérias-primas secas foram inicialmente trituradas e peneiradas. Após pesagem nas devidas proporções, essas foram incorporadas à fração de fígado bovino cru finamente moído, homogeneizadas e peletizadas. A secagem foi realizada em estufa a $40^{\circ} \mathrm{C}$, durante 48 horas. Posteriormente, foram trituradas e peneiradas. Foram administradas aos peixes somente partículas maiores que $1 \mathrm{~mm}$. Os peixes utilizados neste experimento foram criados em tanque de terra e transferidos para tanques de alvenaria por três dias antes do início do experimento, quando receberam a ração base sem lipídios. Foram utilizados 180 peixes, com peso médio inicial de $21,58 \mathrm{~g}$,

Tabela 1 - Composição das dietas experimentais (T) testadas no experimento.

\begin{tabular}{llll}
\hline Ingredientes em (\%) & $\mathrm{T}_{1}$ & $\mathrm{~T}_{2}$ & $\mathrm{~T}_{3}$ \\
\hline Fígado bovino “in natura” (MS) * & 35 & 35 & 35 \\
Levedura de cana & 50 & 50 & 50 \\
Quirera de arroz & 8 & 8 & 8 \\
Premix vitamínico ** & 1,5 & 1,5 & 1,5 \\
Premix mineral*** & 0,5 & 0,5 & 0,5 \\
Óleo de canola & 5 & - & - \\
Óleo de fígado de bacalhau & - & 5 & - \\
Banha suína & & - & 5 \\
\hline
\end{tabular}

* A quantidade de fígado in natura (70\% de umidade) usada foi corrigida para \% MS conforme FONTINELLI (1997).

** Composição por kg de ração: Vit .A: 12.000 UI; Vit. D: 2.000 UI; Vit. E: 200; Vit. K: 10 UI; Riboflavina: 40mg; Ác. Pantotênico: 60mg; Niacina: 120mg; Vit. B12: 40mg; Colina: 500mg; Biotina: 1,2 mcg; Ác. Fólico 5,0mg; Tiamina: 20mg; Pirodoxina: $12 \mathrm{mg}$ e Vit C: 500mg. Segundo FONTINELLI (1997)

*** Composição por kg ração: Mg: 50ppm; S: 400ppm; Mn 40ppm; $\mathrm{Cu}:$ 0,3ppm; Fe 7,5ppm; Zn: 7ppm; Co: 0,7ppm; I: $20 \mathrm{ppm}$ e Cálcareo calcítico $3,625 \mathrm{~g} / \mathrm{kg}$. Segundo FONTINELLI (1997) distribuídos em 9 tanques de fibrocimento contendo $800 \ell$ de água, numa densidade de 20 peixes/tanque. As unidades experimentais constituíam um sistema aberto, sendo o abastecimento e a saída de água individuais, com renovação aproximada de $20 \%$ do volume a cada dois dias. Aos 15 e 26 dias experimentais, todos os peixes de cada unidade experimental foram coletados (com rede confeccionada com tecido filó), colocados em recipientes com água previamente tarados e pesados em balança com capacidade de $5 \mathrm{~kg}$ sem o uso de anestésicos. Para os estudos de rendimento (peixes eviscerados e com cabeça) e composição química da carcaça, foram utilizados todos os exemplares das repetições, realizando-se as análises de composição corporal em: proteína bruta (PB), extrato etéreo (EE), cinzas (CZ) e água. A partir desses dados, foram determinadas a deposição total de proteína e gordura, bem como as taxas de deposição de proteína e de gordura na carcaça, através das seguintes fórmulas descritas por CAMARGO (1995), que são: a) Taxa de deposição de proteína na carcaça: $\mathrm{TDPC}_{(\mathrm{mg} / \mathrm{dia})}=$ PBTD / D x 1000; em que PBTD é a proteína bruta total depositada e D o número de dias de experimento; b) Gordura total depositada: $\mathrm{GTD}_{(\mathrm{g})}=(\mathrm{PF} \times \mathrm{RCF} / 100 \times \mathrm{x} \% \mathrm{EEF}$ $\mathrm{Mn} / 100)$ - (PI x RCI/100 x \% EEI Mn/100) ; em que: PI e PF são os pesos médios inicial e final; RCI e RCF os rendimentos de carcaça inicial e final; e \% EEF Mn e \% EEI Mn são as percentagens de extrato etéreo na matéria natural final e inicial; c) Taxa de deposição de gordura na carcaça: TDGC $_{(\mathrm{mg} / \mathrm{dia})}=$ GTD / D x 1000 , em que: GTD é gordura total depositada e $\mathrm{D}$ o número de dias de experimento.

O arraçoamento foi feito manualmente, duas vezes ao dia, na proporção de $2,7 \%$ da biomassa total. Os parâmetros físicos e químicos da água foram aferidos diariamente, através de um Kit laboratorial (Alfa-tecnoquímica), analisando as seguintes variáveis: temperatura, $\mathrm{pH}$, oxigênio dissolvido, amônia total, nitrito e alcalinidade. A aeração do sistema foi realizada por bombas de ar para aquários.

O delineamento experimental utilizado foi inteiramente casualizado, com três tratamentos e três repetições. Os dados de desempenho foram submetidos à análise de variância, aplicando-se o teste $\mathrm{F}$ em nível de 5\% de significância, utilizando o Pacote Estatístico SAS (SAS, 1993) em um computador IBM 9276, do Centro de Processamento de Dados da UFSM.

\section{RESULTADOS E DISCUSSÃO}

Os resultados dos parâmetros físicoquímicos da água estão relacionados na tabela 2, verificando-se que temperatura, oxigênio dissolvido, 
Tabela 2 - Valores mínimo, máximo e média dos parâmetros físico-químicos da água aferidos durante o experimento.

\begin{tabular}{lccc}
\hline Parâmetros & mínimo & máximo & média \\
\hline Temperatura $\left({ }^{\circ} \mathrm{C}\right)$ & 19,5 & 25,0 & 22,2 \\
Oxigênio $(\mathrm{mg} / \mathrm{L})$ & 5,0 & 9,0 & 6,2 \\
Amônia total $(\mathrm{mg} / \mathrm{L})$ & 0,73 & 1,94 & 1,38 \\
Nitrito $(\mathrm{mg} / \mathrm{L})$ & 0,05 & 0,20 & 0,09 \\
Alcalinidade $(\mathrm{mg} / \mathrm{L})$ & 32,0 & 60,0 & 40,77 \\
pH & 7,0 & 7,5 & 7,46 \\
\hline
\end{tabular}

$\mathrm{pH}$, alcalinidade e amônia total mantiveram-se dentro dos níveis aceitáveis para criação. A sobrevivência observada no experimento foi de $71,66 \%$ nos tratamentos T1 e T3 e 50\% no T3. Para ganho médio de peso e rendimento de carcaça dos juvenis de jundiá (Rhamdia quelen), as três fontes de lipídios utilizadas no experimento não apresentaram diferença significativa $(\mathrm{P}>0,05)$ aos 15 e 26 dias experimentais (Tabela 3). CAMARGO (1995), utilizando óleo de soja como fonte de lipídio em rações para tambaquis, não verificou efeito linear sobre o ganho de peso final. Resultados semelhantes foram encontrados por PEZZATO et al. (1995), quando testaram diferentes níveis de banha de suínos e óleo de soja na alimentação de alevinos de pacu, e obtiveram ganhos médios de peso equivalentes tanto com $8 \%$ de inclusão de gordura vegetal como com $16 \%$ de inclusão de gordura animal.

Em relação ao rendimento de carcaça dos juvenis de jundiá, não houve diferença significativa no rendimento inicial e final. $\mathrm{O}$ rendimento de carcaça final mais alto $(81,56 \%)$ foi obtido com o tratamento T3, não diferindo dos demais. Rendimentos semelhantes foram encontrados por POUEY et al. (1999), quando avaliaram componentes corporais do jundiá Rhamdia sp criados em tanques de terra $\left(1\right.$ peixe $\left./ \mathrm{m}^{2}\right)$ e alimentados com ração comercial, separado-os em quatro faixas de peso, em que obtiveram rendimento de carcaça de 83,24 a 90,06\%. Trabalhando com

Tabela 3 - Valores médios de peso de alevinos de jundiá Rhamdia quelen e rendimentos de carcaça inicial $(\mathrm{RCI})$ e final $(\mathrm{RCF})$ em relação às fontes de lipídios testadas.

\begin{tabular}{lccc}
\hline Variáveis & T1 & T2 & T3 \\
\hline Peso Inicial $(\mathrm{g})$ & 21,58 & 21,58 & 21,58 \\
Peso aos 15 dias (g) & 36,56 & 32,00 & 35,33 \\
Peso aos 26 dias (g) & 44,94 & 41,74 & 38,52 \\
RCI (\%) & 82,42 & 82,42 & 82,42 \\
RCF $(\%)$ & 80,03 & 80,55 & 81,56 \\
\hline
\end{tabular}

Tratamentos: T1- óleo de canola; T2- óleo de fígado de bacalhau; T3- banha suína.
Sardinella brasiliennsis, MANDELLI \& LONA (1978) encontraram rendimento de filé de 40,10\%. Por outro lado, SANTOS et al. (1995) avaliando o rendimento de filé do Hypostomus commersonii, uma espécie nativa do Rio Grande do Sul, criada em condições de alimentação natural, obtiveram valores menores que $20,88 \%$ de rendimento baseado apenas no filé. Estas informações não existem em relação ao rendimento de filé do jundiá, sendo necessária a condução de trabalhos experimentais neste sentido.

A composição corporal final apresentou variações quanto à proteína e à gordura na carcaça (Tabela 4). Com o tratamento T3 (banha suína) obteve-se $24,11 \%$ a mais de gordura em relação à gordura inicial, enquanto que a retenção de proteína manteve-se estável em relação à composição inicial $\mathrm{e}$ às fontes testadas no experimento. ARGYROPOULOU et al. (1992) encontraram resultados semelhantes de aumento de gordura na carcaça de Mugil cephalus na composição final em relação à composição inicial, quando avaliaram o efeito de óleo de peixe, óleo de linhaça, óleo de soja e óleo de milho com nível de inclusão de $8 \%$. Os autores obtiveram na composição corporal valores entre 10,2; 9,12; 9,92 e 9,86\% de gordura total, respectivamente nas quatro fontes de óleo, tendo $5,63 \%$ de gordura na amostra inicial. Para a proteína bruta, os valores finais obtidos foram maiores sendo iguais a 17,$3 ; 18,3 ; 18,1$ e $19,1 \%$, nas quatro fontes de lipídios, enquanto que na amostra inicial foi de $15,7 \%$.

Valores superiores de proteína bruta e menores para gordura na carcaça foram encontrados por KIM et al. (1989), que avaliaram o efeito de diferentes níveis de proteína $(44,0$ e $31,2 \%$ ) e de lipídios $(20,6$ e 9,2\%) na dieta para juvenis de truta arco-íris, num período de 12 semanas, os quais obtiveram 18,5 a $19,6 \%$ de proteína e 5,2 a $5,9 \%$ de gordura na carcaça. Os autores também observaram neste trabalho uma grande aumento do teor de

Tabela 4 - Valores médios ( \%) da composição corporal inicial $(\mathrm{CCI})$ e final $(\mathrm{CCF})$ na matéria natural, em relação às fontes testadas.

\begin{tabular}{lcccc}
\hline & PB & EE & CZ & Água \\
\hline CCI & 14,43 & 2,53 & 3,19 & 76,78 \\
CCF T1 & 13,23 & 3,82 & 3,05 & 74,05 \\
CCF T2 & 12,48 & 4,40 & 2,56 & 75,31 \\
CCF T3 & 13,26 & 5,67 & 2,83 & 73,46 \\
\hline
\end{tabular}

PB - Proteína bruta; EE - Extrato etéreo; CZ - Cinzas e Água (valores em percentagem);

Tratamento: T1 - óleo de canola; T2 - óleo de fígado de bacalhau; T3 - banha suína 
lipídio, sendo que o teor de gordura total inicial foi de $1,9 \%$.

WINFREE \& STICKNEY (1981) testaram diferentes relações energia/proteína para alevinos de Tilapia aurea, utilizando óleo de peixe como fonte de lipídio, e encontraram na composição corporal uma variação de 12 a $17,1 \%$ de $\mathrm{PB}$ e 4,0 a $11,9 \%$ de gordura, com uma relação proteína/energia de 148 de 85 a $148 \mathrm{mg} / \mathrm{Kcal}$ de energia digestível. Nos alevinos de jundiá, constatou-se que a deposição e as taxas de deposição de gordura e proteína na carcaça foram influenciadas pelas fontes de lipídios testadas. O tratamento $\mathrm{T} 1$ depositou $35,85 \%$ a mais de proteína bruta em relação ao tratamento T3 $(86,35 \mathrm{mg} /$ dia contra 63,56mg/dia respectivamente). Para a deposição de gordura, o tratamento T3 apresentou uma taxa superior em relação aos demais, no valor de $51,20 \mathrm{mg} /$ dia, sendo $44,10 \%$ a mais em relação ao T1 (Tabela 5). CAMARGO (1995) avaliou dietas contendo óleo de soja para tambaqui, durante 113 dias, e encontrou maior taxa deposição de proteína na carcaça $(277,35 \mathrm{mg} /$ dia) e taxa de deposição de gordura $(65,15 \mathrm{mg} / \mathrm{dia})$ com nível de energia de $3.300 \mathrm{Kcal} / \mathrm{kg}$ de dieta. Por outro lado, VIDAL JUNIOR (1995) avaliou níveis de proteína para juvenis de tambaqui e considerou como melhores taxas de deposição de proteína e gordura os valores de 231,50 a $311,18 \mathrm{mg} /$ dia de proteína, e 151,61 a $179,15 \mathrm{mg} /$ dia de gordura.

\section{CONCLUSÕES}

Através dos resultados preliminares obtidos no experimento, e como o rendimento de carcaça não foi influenciado pelas fontes testadas, é possível concluir que as três fontes testadas apresentam-se como alternativas para inclusão em

Tabela 5 - Proteína bruta e gordura total depositada e taxa de deposição de proteína e gordura na carcaça, em relação as fontes testadas no experimento.

\begin{tabular}{lllll}
\hline Tratamentos & $\begin{array}{l}\text { PBTD } \\
(\mathrm{g})\end{array}$ & $\begin{array}{l}\text { TDPC } \\
(\mathrm{mg} / \text { dia })\end{array}$ & $\begin{array}{l}\text { GTD } \\
(\mathrm{g})\end{array}$ & $\begin{array}{l}\text { TDGC } \\
(\mathrm{mg} / \mathrm{dia})\end{array}$ \\
\hline T1 & $2,24^{\mathrm{a}}$ & $86,35^{\mathrm{a}}$ & $0,92^{\mathrm{a}}$ & $35,53^{\mathrm{a}}$ \\
T2 & $1,68^{\mathrm{b}}$ & $64,72^{\mathrm{b}}$ & $1,02^{\mathrm{b}}$ & $39,59^{\mathrm{b}}$ \\
T3 & $1,67^{\mathrm{b}}$ & $63,56^{\mathrm{b}}$ & $1,33^{\mathrm{c}}$ & $51,20^{\mathrm{c}}$ \\
\hline
\end{tabular}

Tratamentos: T1- óleo de canola; T2- óleo de fígado de bacalhau; T3- banha suína

Médias seguidas por letras diferentes na coluna, apresentam diferença significativa, pelo teste Tukey $(\mathrm{P}<0,05)$

PBTD- Proteína bruta total depositada

TDPC- Taxa de deposição de proteína na carcaça

GTD- Gordura total depositada

TDGC- Taxa de deposição de gordura na carcaça dietas para juvenis de jundiá, sendo necessário um período experimental mais longo para melhor visualização dos seus efeitos. O uso da banha suína causou maior índice de gordura na carcaça de juvenis de jundiá, e a maior deposição de proteína na carcaça ocorreu com o uso de óleo de canola na dieta.

\section{REFERÊNCIAS BIBLIOGRÁFICAS}

ARGYROPOULOU, V., KALOGEROPOULOS, N., ALEXIS, N. Effect of dietary lipids on growth and tissue fatty acid composition of grey mullet Mugil cephalus. Comp Biochem Physiol, v.101, n.1. p.129-135. 1992.

CAMARGO, A.C.S. Níveis de energia metabolizável para Tambaqui Colossoma macropomum (CUVIER, 1818) dos 30 aos 180 gramas de peso vivo. Viçosa, MG, 1995. 55p. Dissertação (Mestrado em Zootecnia) - Universidade Federal de Viçosa. 1995.

CHO, C.Y., COWEY, C.W., WATANABE, T. Finfish nutrition in Asia: Methodological approaches to research and development. Ottawa, Ontário : International Development Research Center, 1985. 154p.

FARKAS, T., CSENGERI, I., MAZOROS, F., et al. Sem on fish Nutrition and diet Development, S.1. : s.e., 1977. Role of lipids in fish nutrition.: p.58-75,

GATLIN, D.M., STICKNEY, R.R. Fall-winter growth of young channel catfish in response to quantity and source of dietary lipid. Trans Amer Fish Soc, v.111, p.90-93, 1982.

KIM, S.D., KAUSHIK, S.J., PASCAUD, M. Effects of dietary lipid to protein ratios on the fatty acid composition of muscle lipids in rainbow trout. Nutrition Reports International, v.4, n.1, p.9-16, 1989.

LÉGER, C. Dévélopement récents de la notion d'acide gras essentiel chez les poissons. Ann Nutr Alim, 34: 207-216, 1980 .

MANDELlI, M.Q., LONA, F.B. Composição física em princípios imediatos da carne (filés) em Sardinela brasiliennsis (Steindachner, 1979). Bol Inst de Pesca, v.5, n.2, p.129-157, 1978.

NICOLAIDES, N., WOODALL, A.N. Impaired pigmentation in chinook salmon fed diets deficient in essential fatty acids. Journal of Nutrition, v.78, p.431-437, 1962.

PEZZATO, L.E., CASTAGNOLLI, N., BARROS, M.M., $\boldsymbol{e} \boldsymbol{t}$ al. Alevinos de pacu (Piaractus mesopotamicus) arraçoados com diferentes níveis de gordura animal e vegetal. In: ENCONTRO SUL BRASILEIRO DE AQUICULTURA, 3, E ENCONTRO RIOGRANDENSE DE TÉCNICOS EM AQUICULTURA,6, 1995, Ibirubá, RS. Anais... S.1. : s.e., 1995. p.52-59.

POUEY, J.L.O., MIOTTO, H.C., KUNZ, T.L., et al. Principais componentes corporais do jundiá Rhamdia $s p$ cultivado na densidade de um peixe $/ \mathrm{m}^{2}$ e dividido em quatro faixas de peso. In: REUNIÃO ANUAL DA SOCIEDADE. BRASILEIRA DE ZOOTECNIA, 36, 1999, Porto Alegre-RS. Anais... S.1. : s.e., 1999. p.314. 
SAS. Statistical Analises System. User's Guide. Version 6.08, 4ed. North Caroline : SAS INSTITUTE, 1993. 846p.

SANTOS, A.B., MELO, J.F.B., LOPES, P.R.S. Estudo da carcaça do cascudo Hypostommus commersonii, na Região de Uruguaiana-RS/Brasil. In: ENCONTRO SUL BRASILEIRO DE AQUICULTURA, 3 E ENCONTRO RIOGRANDENSE DE TÉCNICOS EM AQUICUlTURA, 6, 1995, Ibirubá, RS. Anais... S.1. : s.e., 1995. p.70-76.
STICKNEY, R.R., HARDY, R.W. Lipid requeriments of some warm-water species. Aquaculture, n.78, p.145-156, 1989.

VIDAL JUNIOR, M.V. Níveis de proteína para tambaqui Colossoma macropomum (CUVIER, 1918) dos 30 aos 250 g de peso vivo. Viçosa, 1995. 46p. Dissertação (Mestrado) Universidade Federal de Viçosa, 1995.

WINFREE, R.A., STICKNEY, R.R. Effects of dietary protein and energy on growth, feed conversion efficiency and body composition of Tilapia aurea. J Nutr, n.111, p.1001-1012, 1981 